\title{
Comparative studies on the photosynthetic characteristics of two maize (Zea mays L.) near-isogenic lines differing in their susceptibility to low light intensity
}

\author{
Chuangjian Qian', Wei Zhang ${ }^{2,3}$, Xuemei Zhong', Fenghai Li ${ }^{1}$, and Zhensheng Shi ${ }^{1 *}$ \\ ${ }^{1}$ Department of Agronomy, Special Corn Research Institute, Shenyang Agricultural University, Shengyang 110866, PR China, ${ }^{2}$ Department of \\ Agronomy, Rice Research Institute, Shenyang Agricultural University, Shengyang 110866, PR China, ${ }^{3}$ Rice Research Institute, Academy of \\ Agricultural Sciences of Jilin city, Jilin 132000, PR China
}

\section{A B S T R A C T}

\begin{abstract}
The objective of our study was to quantify the effect of low light intensity on chlorophyll (Chl) content, photosynthetic parameters, chlorophyll fluorescence parameters and growth of two maize (Zea mays L.) near-isogenic lines (NILs) differing in their susceptibility to low light to reveal the cause of the resistance to weak light in maize. A field-experiment was conducted in the central plain of Liaohe river in northeast China $\left(41^{\circ} 49^{\prime} \mathrm{N}, 123^{\circ} 34^{\prime} \mathrm{E}\right)$, on a meadow brown soil. Two levels of photosynthetically-active radiation (removal of $0 \%$ and $40 \%$ of sunlight) were tested on SN98A (shading sensitive) and SN98B (shading tolerant) lines. The results showed that shading lengthened the anthesis-silking interval (ASI), increased the percentage of barren stalk and reduced the percentage of silking, and shading decreased leaf $\mathrm{Chl}$ content, net photosynthetic rate (Pn), quantum yield of PSII (Y(II)), electron transport rate (ETR), and photochemical quenching (qP) in the two maize NILs. The shading tolerances differed between different near-isogenic lines. Maximum efficiency of PSII photochemistry under dark-adaption $\left(\mathrm{F}_{\mathrm{v}} / \mathrm{F}_{\mathrm{m}}\right)$ of SN98B was increased under low light intensity; meanwhile relatively more stable contents of $\mathrm{Chl}, \mathrm{Pn}, \mathrm{Y}(\mathrm{II}), \mathrm{ETR}$, and $\mathrm{qP}$ were able to enhance light-use efficiency and reduce the dissipation of light energy, relieving the reduction in photosynthetic efficiency which caused reduced production of ear assimilative products, thus resulting in a smaller reduction in percentage of barren stalk in SN98B under shading. These findings demonstratethat low light intensity depressed photosynthetic activity and growth of SN98A more than that of SN98B. SN98A could be more restricted by limited carbon assimilation, leading to the production of more barren stalks in low light intensity compared to SN98B. Therefore, improvements in light-harvesting and -use capability and increasing ear filling under low light intensity stress might be important characteristics for plant breeders. Selection of SN98B as a shade-tolerant germplasm for breeding in maize would alleviate the problem of barren stalk development under low light intensity.
\end{abstract}

Keywords: Barren stalk; Near-isogenic lines; Photosynthetic characteristic; Weak light stress

\section{INTRODUCTION}

Together with advances in germplasm and cultivation measures, the environment plays an important role in grain quality improvement of maize(Zea mays L.). In concert with ambient temperature, available water resources, and soil nutrients, ambient light is also an important factor impacting the growth and development of plants; sunlight absorbed by plants is used as an energy source in the photosynthetic pathway (Cui et al., 2015). In this process, ATP and NADPH are produced using light energy in the light reaction, followed by the conversion of carbon into carbohydrates and oxygen in the light-independent reaction (Dai et al., 2009). The grain yield of a corn plant is the result of the number of grains multiplied by the grain weight on each corn ear, which is dependent on the capacity of the plant's leaves (the source tissues) to generate photoassimilates, and that of the grain kernels (the sink tissues) to convert those photoassimilates into grain yield (Zhang et al., 2001; Tuncel and Okita, 2013). As a result, a plant's capacity to produce photoassimilates (sources) is a significant element limiting grain production (Miralle and Slafer, 2007). Unfortunately, climate change is an indisputable fact, caused by the increase in density of

\footnotetext{
*Corresponding author:

Zhensheng Shi, Department of Agronomy, Special Corn Research Institute, Shenyang Agricultural University, Shengyang 110866, PR China. E-mail: qianchjian366@163.com
} 
population, haze, and atmospheric pollution, and as a result dimming or low light intensity are the main challenges to productivity of crops in many countries (Mu et al., 2010). Global radiation has been reduced by $1.4-2.7 \%$ per decade between $25^{\circ} \mathrm{N}$ and $45^{\circ} \mathrm{N}$ (Forster and Ramaswamy, 2007; Ramanathan and Feng, 2009). In China, the period of productive radiation reduced by $1.28 \%$ per decade between 1960 and 2000 (Che et al., 2005). Taking Shenyang City in Liaoning Province (location of our experimental plots) as an example, the annual average duration of sunlight was $195 \mathrm{~h}$ less than that over the years 1996 to 2005, which in turn was lessened by $179 \mathrm{~h}$ compared with the years 1986 and 1995, because there was an increase in the number of rainy and cloudy days (Shenyang municipal bureau of meteorology, 2013). Liaoning Province in northeast China is a major production region for maize, where the continuous rainy season often coincides with the maize reproductive stage. Only if the duration of solar radiation exceeds $600 \mathrm{~h}$ through the summer maize-growing period, can the maize achieve a high yield (Cui et al., 2015). A decrease of $1 \mathrm{~kJ} \mathrm{~cm}^{-2}$ in sun radiation through the maizegrowing stage will lead to a decrease of $338 \mathrm{~kg} \mathrm{ha}^{-1}$ in crop biomass (Wu, 1991).

Most studies to date have used shading to investigate the effects of low intensity light on crop growth and development (Xu et al., 2013; Cui et al., 2015). Many studies have shown that shade treatment not only reduces the intensity of light but also increases the diffuse light proportion (Gu et al., 2002; Greenwald et al., 2006) and changes the light spectral quality (Bell et al., 2000). However, diffuse light can be more efficiently absorbed by a crop, and can compensate for reductions in direct light, and ultimately, reinforce crop leaf $\mathrm{CO}_{2}$ assimilation and photoassimilation (Cohan et al., 2002). In addition, under shaded conditions, the proportions of the spectrum are altered, with an increase in blue light and a reduction in red light content (Bell et al., 2000), all factors which influence the growth and development of plants (Casal, 1988; Barnes and Bugbee, 1992; Furuya et al., 1997).

The main effect of shade treatment in the crop growth environment is to reduce the intensity of the incident light (Chan and Mackenzie, 1972). This change results in variations in plant morphology, plant physiology, crop biomass, crop grain yield, and crop quality (Early et al., 1967; Vityakon et al., 1993; Li et al., 2010; Mu et al., 2010; Wang et al., 2013). Levels of the crucial photosynthetic pigments, $\mathrm{Chl}$ a and $\mathrm{Chl}$ b, decrease in leaves under shading, and it is likely that there are fewer mesophyll cells per unit leaf area under shade conditions (Senevirathna et al., 2003). The photosynthesis, photochemical efficiency, and nonphotochemical quenching of plants are also decreased by shading (Dai et al., 2009; Mu et al., 2010), and consequently, the dry matter accumulation of plants is reduced and the reallocation of photoassimilates is disturbed (Vityakon et al., 1993; Acreche et al., 2009). Eventually, flowering is delayed, grain yield is reduced, and in addition quality is changed as a result of shading (Mu et al., 2010; Cai, 2011; Wang et al., 2013; Liu et al., 2015).

To date, most studies have focused on the effects of low solar radiation on crop growth and development. However, there have been few reports on the differences among cultivars in their sensitivity to low light intensity. Further, the impact of low light intensity on photosynthetic characteristics, barren stalk, and the relationships between the two has not been documented in leaves of maize. Barren stalk in our study refers to the complete lack of maize ear organs; not only are there no flowers, but even the maize ear initials in the maize plantare lacking (Kanellis et al., 1999). Zhong et al. (2014) demonstrated that low light intensity would cause barren stalk in different varieties and showed that differences among varieties were obvious. Past studies on photosynthesis were mainly conducted on different genotype cultivars. However the complexity of genetic backgrounds of cultivars used in the research into photosynthesis has led to some inaccuracies in the further study of the pivotal regulatory process and the precise reaction site of photosynthesis in maize.

To address this issue, our experiment was carried out in one field with two maize near-isogenic lines (NILs) (SN98A and SN98B) with significant differences in barren stalk formation, to explore the relationship between photosynthetic characteristics and maize ear development. In previous studies carried out by our team, in which the impacts of shade treatments implemented at different growth stages and the levels of shading in SN98A and SN98B were studied, we demonstrated that shading reducing light intensity to $60 \%$ of ambient sunlight, applied $10 \mathrm{~d}$ before tasseling to the end of silking, resulted in barren stalk (Zhong, 2014). The chief purposes of this article were: (1) to assess the effect of low light intensity on chlorophyll content, chlorophyll fluorescence characteristics, and photosynthetic characteristics of the two maize lines; (2) to compare the differences in the responses of the two maize lines to low light intensity; and (3) to choose some shade-tolerance indexes for maize production. Furthermore, our findings regarding improvements to maize cultivars under adverse abiotic conditions will provide valuable information to maize breeders.

\section{MATERIALS AND METHODS}

\section{Field design}

The field experiment was conducted in 2015 at the Experimental Station of Shengyang Agricultural University, 
Shengyang $\left(41^{\circ} 49^{\prime} \mathrm{N}, 123^{\circ} 34^{\prime} \mathrm{E}\right)$, Liaoning Province, PR China, which has a typical semi-humid temperate continental monsoon climate. The region displays a mean annual temperature of $8^{\circ} \mathrm{C}$ with precipitation of $628 \mathrm{~mm}$, average light intensity of $793 \mu \mathrm{molm}^{-2} \mathrm{~s}^{-1}$ from May to September and a frost-free period of about 150-170 d. The accumulated temperature of periods above $10^{\circ} \mathrm{C}$ is $3300-3400^{\circ} \mathrm{C}$. The annual rainfall tends to occur over a short period while the air temperature is very variable (Sui et al., 2016). Assessment of the basic properties of the soil showed that it contained $25.5 \mathrm{~g} \mathrm{~kg}^{-1}$ organic matter, $2.42 \mathrm{~g} \mathrm{~kg}^{-1}$ total $\mathrm{N}, 105.6 \mathrm{mg} \mathrm{kg}^{-1}$ available $\mathrm{N}, 12.9 \mathrm{mg} \mathrm{kg}^{-1}$ available $\mathrm{P}$ and $100.4 \mathrm{mg} \mathrm{kg}^{-1}$ available $\mathrm{K}$. In this study, we used two maize near-isogenic lines (Shennong 98A and Shennong 98B) with significant differences in response to weak light (Zhong et al., 2014). Shennong 98A (SN98A, shading sensitive) and Shennong 98B (SN98B, shading tolerant) were a pair of near-isogenic lines (NILs) isolated from a high-generation hybrid combination. With shading of $40 \%$ of the full radiation from $10 \mathrm{~d}$ before tasseling, the ears of SN98A developed abnormally, developing severe barren stalk, but the ears of SN98B developed normally, as expected based on the results of a previous field-based investigation (Zhong, 2014). The sowing date was the $15^{\text {th }}$ of May 2015, at a plant density of 60,000 plant ha $\mathrm{a}^{-1}$, and emergence took place $15 \mathrm{~d}$ later. A dose of $378 \mathrm{~kg} \mathrm{~N} \mathrm{ha}{ }^{-1}, 202.5 \mathrm{~kg} \mathrm{P}_{2} \mathrm{O}_{5} \mathrm{ha}^{-1}$, and $162 \mathrm{~kg} \mathrm{~K}_{2} \mathrm{O} \mathrm{ha}^{-1}$ was applied before sowing.

The experiment was a split-plot design with light intensities as the main plot and maize cultivar as subplot. Every experimental plot was $60 \mathrm{~m}^{2}(5 \times 12 \mathrm{~m})$ in size and consisted of twenty rows of maize spaced $0.6 \mathrm{~m}$ apart. To provide low light intensity treatment, the top of the maize canopy was covered with one layer of black net screensto provide shading $(\mathrm{S})$ starting from $10 \mathrm{~d}$ before tasseling to 25 dafter starting treatment, a period designated as 'days after shading' (DAS). The screens blocked about $40 \%$ of the ambient sunlight above the canopy. Ambient sunlight treatment was set as the control $(\mathrm{L})$. A distance of $1 \mathrm{~m}$ between the black net screens and the top of the maize canopy was maintained to keep the microclimate under the screens consistent with the control (Fig. 1A).

\section{Meteorological measurements}

Irradiance was measured with an AccuPAR model LP-80 plant canopy analyzer (LI-COR Biosciences Inc., Lincoln, NE, USA) more than $30 \mathrm{~cm}$ above the maize canopy. Maize population $\mathrm{CO}_{2}$ concentration and relative humidity were measured with a portable open photosynthesis system (LI-6400XT; LI-CORBiosciences Inc.) and air temperature with a normal thermometer at mid-plant height before the tasseling stage and at ear height after the tasseling stage. Wind speed was measured with an AR816 anemometer
(Huier Analytical Instrument Company, Hangzhou, China). All measurements were taken daily at 11:00 a.m. for 5 days after shading, and means were calculated (Table 1).

\section{Sampling and measurements Growth and development process}

The progress of maize growth was investigated daily from sowing to maturity. The stages of growth and development were recorded (based on $50 \%$ of all plants in the plot attaining the growth stage) in detail at 10:00 a.m. each day.

\section{Pollen-shedding duration}

Ten plants in each plot which exhibited uniformity in size and developmental stage were labeled and used to quantify the duration of powder from the start to the end.

\section{Chlorophyll content}

Samples were collected at 10, 15, 20, and 25 DAS. Leaves $(0.2 \mathrm{~g})$ from each plot were sampled, the midrib was removed, then the leaf tissue was sliced and incubated with $25 \mathrm{~mL}$ of extraction solution containing equal volumes of acetone and anhydrous ethanol. After complete extraction in the dark at room temperature, the homogenate was centrifuged at $14,000 \times g$ for $30 \mathrm{~min}$ at $25^{\circ} \mathrm{C}$, and the supernatant was used for determination of $\mathrm{Chl}$ content using a Shimadzudouble beam double monochromator UV-visible spectrophotometer (UV-2550, Shimadzu Corporation, Kyoto, Japan) at $663 \mathrm{~nm}$ and $647 \mathrm{~nm}$. The concentration of Chl was colorimetrically analyzed according to the method of Arnon (1949).

\section{Photosynthetic parameters and chlorophyll fluorescence}

$\mathrm{P}_{\mathrm{n}}$, stomatal conductance $(\mathrm{Gs})$, and intercellular $\mathrm{CO}_{2}$ concentration $(\mathrm{Ci})$ of the ear leaves were measured with an LI-6400XT Portable Open Photosynthesis System (LI-COR) from 10:00 to 11:30 a.m. at 10, 15, 20, and 25 DAS. The chamber was equipped with a red/blue LED light source. The photosynthetically-active radiation (PAR) was set at 1,200 $\mu_{\text {molm }}^{-2} \mathrm{~s}^{-1}$. Measurements were carried out with an open system and the leaf chamber temperature was set at $25^{\circ} \mathrm{C}$. A mean value was calculated from three leaves from separate plants ineach plot.

Chlorophyll fluorescence parameters of the ear leaves for the Pn analysis were measured with a portable Chl fluorimeter (PAM-2500, Heinz Walz, Effeltrich, Germany) from 10:00 to 11:30 a.m. at 10, 15, 20, and 25 DAS. The minimum and maximum fluorescence $\left(\mathrm{F}_{0}\right.$ and $\left.\mathrm{F}_{\mathrm{m}}\right)$ were determined after full-dark adaptation for $30 \mathrm{~min}$. Then the leaves were continuously irradiated with white actinic light $\left(619 \mu \mathrm{molm}^{-2} \mathrm{~s}^{-1}\right)$ to measure the minimum fluorescence yield $\left(\mathrm{F}_{0}^{\prime}\right)$ and maximum fluorescence yield $\left(\mathrm{F}_{\mathrm{m}}{ }^{\prime}\right)$ of irradiated leaves. By using fluorescence parameters determined 
Table 1: Microclimate in a maize experimental field with shading treatment (S) $(60 \%$ of ambient sunlight via black net screens $1 \mathrm{~m}$ above the maize canopy) and ambient sunlight (L), measurements were taken at 11:00 a.m. for 5 dafter shading, canopy measurements were taken at half plant height prior to tasseling stage and at ear height after tasseling stage, data shown are the means of three replicates

\begin{tabular}{llccccc}
\hline Cultivars & Treatment & $\begin{array}{c}\text { Light intensity } \\
\left(\mu \mathrm{molm} \mathbf{s}^{-1}\right)\end{array}$ & Air temperature $\left({ }^{\circ} \mathrm{C}\right)$ & $\begin{array}{c}\text { Relative } \\
\text { humidity }(\%)\end{array}$ & Air speed $\left(\mathrm{ms}^{-1}\right)$ & $\mathrm{CO}_{2}{\mathrm{concentration}\left(\mu \mathrm{mol} \mathrm{mol}^{-1}\right)}$ \\
\hline SN98A & $\mathrm{L}$ & $1353.6 \mathrm{a}$ & $30.5 \mathrm{a}$ & $55.2 \mathrm{a}$ & $1.1 \mathrm{a}$ & $358.3 \mathrm{a}$ \\
& $\mathrm{S}$ & $835.7 \mathrm{~b}$ & $29.6 \mathrm{a}$ & $56.1 \mathrm{a}$ & $1.1 \mathrm{a}$ & $370.5 \mathrm{a}$ \\
SN98B & $\mathrm{L}$ & $1363.9 \mathrm{a}$ & $30.3 \mathrm{a}$ & $55.8 \mathrm{a}$ & $0.9 \mathrm{a}$ & $360.1 \mathrm{a}$ \\
& $\mathrm{S}$ & $848.6 \mathrm{~b}$ & $29.8 \mathrm{a}$ & $58.3 \mathrm{a}$ & $0.8 \mathrm{a}$ & $376.1 \mathrm{a}$ \\
\end{tabular}

Different letters in each column for each cultivar indicate significant differences between $\mathrm{L}$ and $\mathrm{S}$ at $P<0.05$ analyzed by the least significant difference (LSD) test

on both light- and dark-adapted leaves, the following parameters were calculated: the maximum photochemical quantum yield of PSII, $\mathrm{F}_{\mathrm{v}} / \mathrm{F}_{\mathrm{m}}=\left(\mathrm{F}_{\mathrm{m}}-\mathrm{F}_{0}\right) / \mathrm{F}_{\mathrm{m}}$ (Kitajima and Butler, 1975), the effective photochemical quantum yield of PSII, Y(II) $=\left(\mathrm{F}_{\mathrm{m}}{ }^{-}-\mathrm{F}^{\prime}\right) / \mathrm{F}_{\mathrm{m}}{ }^{\prime}($ Genty et al., 1989), the coefficient photochemical fluorescence quenching, $\mathrm{qP}=\left(\mathrm{F}_{\mathrm{m}}{ }^{\prime}-\mathrm{F}_{\mathrm{t}}\right) /\left(\mathrm{F}_{\mathrm{m}}{ }^{\prime}-\mathrm{F}_{0}{ }^{\prime}\right)$ (van Kooten and Snel, 1990), and apparent photosynthetic electron transport rate, ETR $=\mathrm{Y}(\mathrm{II}) \times \mathrm{PAR} \times 0.84 \times 0.5$, where $\mathrm{PAR}$ represents the photosynthetically-active radiation generated by the internal halogen lamp of the instrument, transport of one electron requires absorption of two quanta, as two photosystems are involved (factor 0.5 ), and it is assumed that $84 \%$ of incident quanta are the absorption coefficient in the advanced plant (factor 0.84).

\section{Statistical analysis}

Microsoft Excel software was used for data processing, and GraphPad Prism 5.0 for mapping. One-way analysis of variance $(A N O V A)$ among treatments or between cultivars was based on the least significant difference (LSD) test at the 0.05 probability level $(P<0.05)$, analyzed by the statistical software package IBM SPSS 20.0 (IBM Corp., Armonk, NY, USA).

\section{RESULTS}

\section{Growth and development}

Tasseling (VT), ear emergence (EE) and silking (R1) were all delayed by low light intensity treatment in both SN98A and SN98B compared to the ambient sunlight control treatment (Table 2). Low light intensity treatment, in comparison to ambient sunlight, increased the number of leaves and prolonged the ASI and duration of pollen shedding (DPS) for each cultivar. Compared with ambient sunlight treatment, the differences observed in growth and development of SN98A under low light intensity conditions were greater than those observed in SN98B (Table 2). Compared to L, $\mathrm{S}$ delayed attainment of EE by $1 \mathrm{~d}$, and R1 was reached $5 \mathrm{~d}$ later in $\mathrm{S}$ than $\mathrm{L}$ groups of SN98A. Meanwhile low light intensity delayed VT, EE and $\mathrm{R} 1$ by $1 \mathrm{~d}, 2 \mathrm{~d}$ and $1 \mathrm{~d}$ respectively in SN98B. Compared with L, S delayed the DPS by $3 \mathrm{~d}$ in SN98A, but before silking, the pollen had dissolved. There were $6 \mathrm{~d}$ for pollination under $\mathrm{S}$ and $\mathrm{L}$ in SN98B. The anthesis-silking interval (ASI) of SN98A was lengthened by $4 \mathrm{~d}$ compared to the ambient sunlight control treatment, while that was unchanged in SN98B. Compared with L, S caused the development of one additional corn leaf in both SN98A and SN98B. The percentage of barren stalk of SN98A under $\mathrm{S}$ was $82.2 \%$ higher than $\mathrm{L}$, while the percentage of barren stalk of SN98B under S was only $18.9 \%$ higher than $\mathrm{L}$. In addition, there was either no ear initiation or the development of dysplastic ears in SN98A under S (Fig. 1D, E, F), while ear development in SN98B under $\mathrm{S}$ was normal compared to L (Fig. 1B, C). Consequently, there were significant differences $(P<0.05)$ between the two maize NILs in yield (Table 2). Under L, the yield of SN98B, at $3,710.09 \mathrm{~kg} / \mathrm{hm}^{2}$, was $37.03 \%$ higher than that of SN98A, and under S there were no yield data for SN98A, because of the $100 \%$ barren stalk.

\section{Silking and pollen-shedding characteristics}

The dynamic processes of pollen shedding and silking were influenced by low light intensity treatment in both maize NILs (Fig. 2), while the influence of low light intensity on SN98A was less than that on SN98B. Under conditions of ambient sunlight, pollen-shedding by SN98A was a little earlier than SN98B, and the DPS was short, lasting only $8 \mathrm{~d}$ (Fig. 2A, Table 2), while in SN98B the DPS lasted $10 \mathrm{~d}$, with pollen-shedding occurring throughout the 10 -day period.

Low light intensity significantly suppressed the percentage of silking in the two maize NILs (Fig. 2B), but caused a greater reduction in SN98A. The percentage of silking was reduced $42.2 \%$ under low light intensity treatment in SN98A at the end of silking, while the reduction was only 5.31\% in SN98B. The percentage reduction in silking of SN98A was significantly greater than that of SN98B, indicating that the percentage of silking in SN98A was more sensitive to low light intensity than in SN98B. At the end of pollen-shedding (4 August), the percentage of silking in SN98A under low light intensity treatment was only about $30 \%$, which seriously affected pollination. 
Table 2: Effects of low light intensity ( $60 \%$ of ambient sunlight via black net screens $1 \mathrm{~m}$ above the maize canopy, S) compared to ambient sunlight (L) on the developmental progress of the maize NILs SN98A and SN98B

\begin{tabular}{|c|c|c|c|c|c|c|c|c|c|}
\hline Cultivar & Treatment & $\begin{array}{c}\text { VT } \\
\text { (month/day) }\end{array}$ & $\begin{array}{c}\text { EE } \\
\text { (month/day) }\end{array}$ & $\begin{array}{c}\text { R1 } \\
\text { (month/day) }\end{array}$ & ASI (d) & $\begin{array}{c}\text { DPS } \\
\text { (month/day) }\end{array}$ & $\begin{array}{l}\text { No. of leaves } \\
\text { per plant }\end{array}$ & $\begin{array}{l}\text { Barren stalk } \\
\text { percentage (\%) }\end{array}$ & Yield $\left(\mathrm{kg} / \mathrm{hm}^{2}\right)$ \\
\hline \multirow[t]{2}{*}{ SN98A } & $\mathrm{L}$ & $7 / 24$ & $7 / 23$ & $8 / 2$ & 10 & $7 / 28-8 / 4$ & 20 & 17.8 & $3178.56 \pm 118.62 b$ \\
\hline & $S$ & $7 / 24$ & $7 / 24$ & $8 / 7$ & 14 & $7 / 28-8 / 7$ & 21 & 100 & - \\
\hline \multirow[t]{2}{*}{ SN98B } & L & $7 / 27$ & $7 / 23$ & $8 / 1$ & 6 & $7 / 29-8 / 7$ & 21 & 11.6 & $4355.46 \pm 108.83 a$ \\
\hline & S & $7 / 28$ & $7 / 25$ & $8 / 2$ & 6 & $7 / 30-8 / 8$ & 22 & 30.5 & $2362.36 \pm 65.18 \mathrm{c}$ \\
\hline
\end{tabular}

Values are the means \pm SE. -, indicates no data recorded, the mean values followed by the same lowercase letters in each column for each cultivar are not significantly different when analyzed by the least significant difference (LSD) test at $P<0.05$, VT, tasseling; EE, ear emergence; R1, silking; ASI, anthesis-silking interval; DPS, duration of pollen shedding

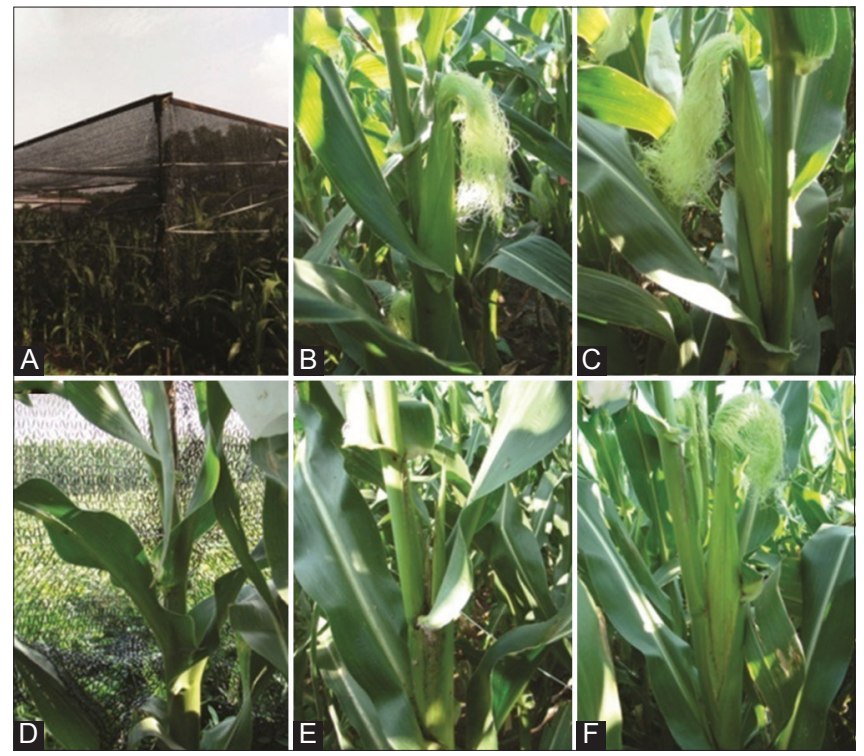

Fig 1. Photograph of the experimental field showing a shaded block (black net screens) (A). Ear development of the two maize NILs SN98B and SN98A under L (C: SN98B; F: SN98A) and S (B: SN98B; D and E: SN98A). All photographs were taken on the same day, after silking. $\mathrm{L}$ indicates ambient sunlight treatment, $\mathrm{S}$ indicates low light intensity treatment.

\section{Chlorophyll content}

Low light intensity stress, compared with ambient sunlight treatment, reduced the chlorophyll (Chl) content in the leaf by increasing the content of both $\mathrm{Chl}$ a and $\mathrm{Chl} \mathrm{b}$ (Fig. 3A-F). The content of $\mathrm{Chl}$ a and $\mathrm{Chl} b$ reduced initially and then increased under both low light intensity and ambient sunlight treatments. The carotenoid (Caro) content of the leaves showed a similar response pattern to that of Chl content in responding to low light intensity (Fig.3G, H). The total $\mathrm{Chl}$ and Caro contents decreased in the leaves of plants grown under low light intensity by 10.0 and $8.97 \%$, respectively, in SN98A, and by 6.29 and $4.28 \%$, respectively, in SN98B, compared with ambient sunlight treatment. However, the response of $\mathrm{Chl} \mathrm{a} / \mathrm{b}$ levels to low light intensity were different in the two maize NILs (Fig. 3I, J). The levels of $\mathrm{Chl} \mathrm{a/b} \mathrm{decreased} \mathrm{in} \mathrm{the}$ leaves of SN98A under low light intensity at 15 DAS, and in SN98B from 10 to 25 DAS.

\section{$\mathrm{P}_{\mathrm{n}}$ and its correlative parameters}

In both maize NILs, Pn and Gs of the leaf were significantly reduced under low light intensity, while there was no significant difference in the $\mathrm{Ci}$ of the leaf under low light intensity from 10 to 20 DAS except in SN98B at 15 DAS (Fig. 4). Pn, Gs, and Ci decreased in the leaf under low light intensity by $36.0,48.8$, and $24.6 \%$, respectively, in SN98A, and by $16.2,29.6$, and $25.7 \%$ in SN98B, compared with ambient sunlight treatment. At 25 DAS, Pn and Gs of the leaf under low light intensity were higher than under ambient sunlight in SN98A, but lower than ambient sunlight in SN98B. However, low light intensity showed the same effect on $\mathrm{Ci}$ of the leaf, which was lower than under ambient sunlight in the two maize NILs; showing a reduction of $18.9 \%$ in SN98A and $17.1 \%$ in SN98B.

\section{Chlorophyll fluorescence of the two maize NILs}

Low light intensity exerted different effects on chlorophyll fluorescence parameters of leaves from the two maize NILs (Fig. 5). Leaf $\mathrm{F}_{\mathrm{v}} / \mathrm{F}_{\mathrm{m}}$ increased under low light intensity in SN98B, while it decreased initially and then increased in SN98A, compared with ambient sunlight treatment. The Y(II) and ETR of the two maize NILs increased under low light intensity by 3.55 and $3.14 \%$ in SN98A, and by 12.7 and $13.5 \%$ in SN98B, compared with ambient sunlight treatment from 10 to 15 DAS. After 20 DAS, the Y(II) and ETR decreased by 18.2 and $17.2 \%$, respectively, in SN98A, and by 16.9 and $16.7 \%$, respectively, in SN98B (Fig. 5B, C) compared with ambient sunlight treatment. The qP under low light intensity was lower than that in ambient sunlight (except for 10 DAS of SN98B) in the two maize NILs.

To evaluate relationships between gas exchange parameters (Pn, Gs, Ci), Chl content and chlorophyll fluorescence parameters $\left(\mathrm{F}_{\mathrm{v}} / \mathrm{Fm}, \mathrm{Y}(\mathrm{II}), \mathrm{ETR}, \mathrm{qP}\right)$ across the sampling dates, linear correlation matrices involving the parameters were calculated for each sampling date, using mean values of the parameters for the two maize NILs grown under both low light intensity and ambient sunlight treatment. Although the two maize NILs displayed some correlations among the photosynthetic parameters, the differences between tolerant and susceptible maize lines under low 


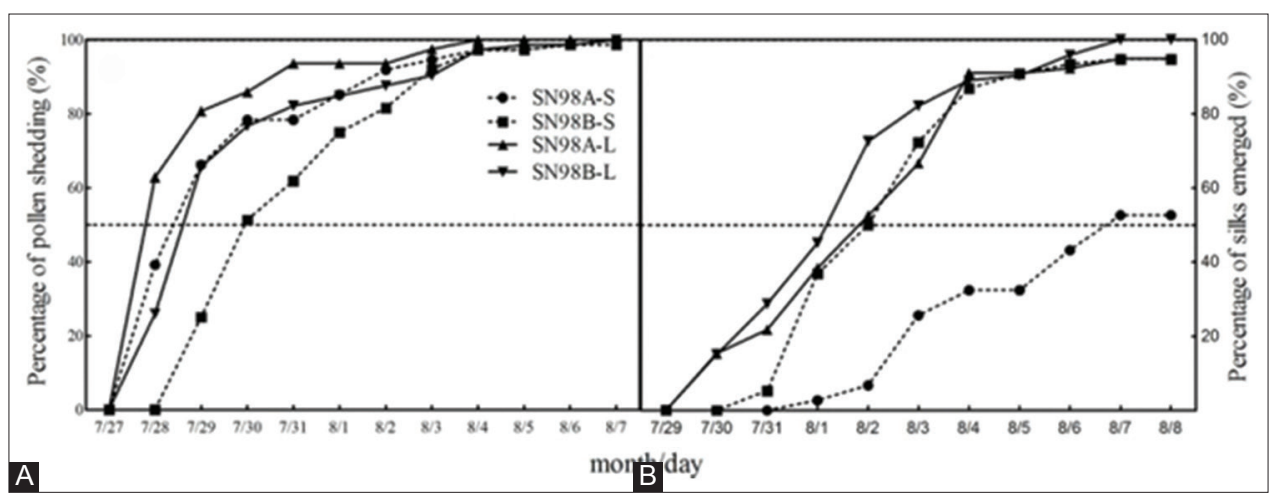

Fig 2. Effects of low light intensity (60\% of ambient sunlight via black net screens $1 \mathrm{~m}$ above the maize canopy) on the silking and pollen-shedding characteristics of two maize NILs. SN98A/B-S refers to low light intensity treatment of NILs SN98A or B; SN98A/B-L refers to ambient sunlight treatment of NILs SN98A or B.

light intensity were not significant, so we have only listed the data for 20 and 25 DAS (Table 3, other data not shown). In our study, it should be noted that correlations between $\mathrm{F}_{\mathrm{v}} / \mathrm{F}_{\mathrm{m}}$ and $\mathrm{Pn}, \mathrm{Gs}, \mathrm{Ci}$, and $\mathrm{Chl}$ content were negative. $\mathrm{Y}(\mathrm{II}), \mathrm{ETR}$ and $\mathrm{qP}$ were significantly $(P<0.05)$ positively correlated with $\operatorname{Pn}(r=0.753, r=0.744, r=0.716$, respectively), and $\mathrm{Y}(\mathrm{II})$, ETR and qP were also significantly $(P<0.05)$ positively correlated with $\mathrm{Chl}$ content $(r=0.805$, $r=0.797, r=0.789$, respectively). However, Ci tended to be negatively associated with $\mathrm{F}_{\mathrm{v}} / \mathrm{F}_{\mathrm{m}}, \mathrm{Y}(\mathrm{II})$, ETR and $\mathrm{qP}$, but a positive correlation was found between some chlorophyll fluorescence parameters and Gs, except for $\mathrm{F}_{\mathrm{v}} / \mathrm{F}_{\mathrm{m}}$.

\section{DISCUSSION}

\section{Effects of low light intensity on growth and development}

The duration and intensity of light radiation are significant for production of stable, high yields of corn. Many studies have shown that low light intensity applied in the course of the reproductive stage of maize influenced grain yield more than when applied in the course of the vegetative growth period (Li et al., 2005). Cui et al. (2015) showed that the vegetative and reproductive stages of corn were both delayed by low light intensity, and an imbalance between maize ear and tassel development was caused by low light intensity, leading to delayed silking relative to pollen shedding. Adverse environmental factors such as high temperature and chilling, waterlogging and drought, and weak light, could result in lengthening of the ASI (Grant et al., 1989; Zhou et al., 2013). Barren stalk as a result of unfertilized ears due to ASI lengthening increased under extremely adverse conditions (Otegui, 1995; Zhong et al., 2014). Our findings show that the pollen shedding date of tassels and the emergence of ears suffered significant delays, with maize ear development being influenced more than that of maize tassels, leading to lengthening of the ASI and resulting abortive fertilization in the course of
Table 3: Genotypic correlation coefficients for associations between net photosynthetic rate (Pn), stomatal conductance (Gs), intercellular $\mathrm{CO}_{2}$ concentration (Ci), chlorophyll (Chl) content and chlorophyll fluorescence parameters (maximum photochemical quantum yield of PSII, $F_{v} / F_{m}$; effective photochemical quantum yield of PSII, Y (II); apparent photosynthetic electron transport rate, ETR; coefficient photochemical fluorescence quenching, $\mathrm{qP}$ ), using mean values of two maize NILs SN98A and SN98B grown under two light treatments $(60 \%$ of ambient sunlight via black net screens $1 \mathrm{~m}$ above the maize canopy and ambient sunlight) measured on day 20 and day 25 after shading

\begin{tabular}{|c|c|c|c|c|}
\hline & $F_{v} / F_{m}$ & Y (II) & ETR & $q P$ \\
\hline $\mathrm{Pn}$ & -0.447 & $0.753^{*}$ & $0.744^{*}$ & $0.716^{*}$ \\
\hline Gs & -0.567 & 0.618 & 0.617 & 0.593 \\
\hline $\mathrm{Ci}$ & -0.452 & -0.195 & -0.171 & -0.167 \\
\hline Chl content & -0.252 & $0.805^{\star}$ & $0.797^{\star}$ & $0.789^{*}$ \\
\hline
\end{tabular}

the flowering stage in the two maize NILs. In addition, the effects were much greater in SN98A than in SN98B. Compared with ambient sunlight treatment, the percentage increase in barren stalk under $\mathrm{S}$ was $82.8 \%$ in $\mathrm{SN} 98 \mathrm{~A}$, but only $18.9 \%$ in SN98B. In addition, the percentage of silking was only about $30 \%$ under low light intensity in SN98A. Consequently the yield superiority of shade-tolerant maize (SN98B) (Table 2) was due to its capacity to sustain a lower percentage of barren stalk compared to susceptible maize (SN98A) under low light intensity, as the variation in barren stalk percentage was highly correlated with yield variation (O'Neill et al., 2006). All of these findings indicated that SN98A was more sensitive to low solar radiation than SN98B.

Contrasting the impacts of low light intensity on Chl and photosynthetic characteristics of the two maize NILs

Light is a key factor which can affect plant photosynthesis; low light radiation results in limited plant growth, which is attributed to the decrease of the photosynthetic rate. Compared to ambient sunlight treatment, shading weakened the photosynthesis of single leaves, and reduced 


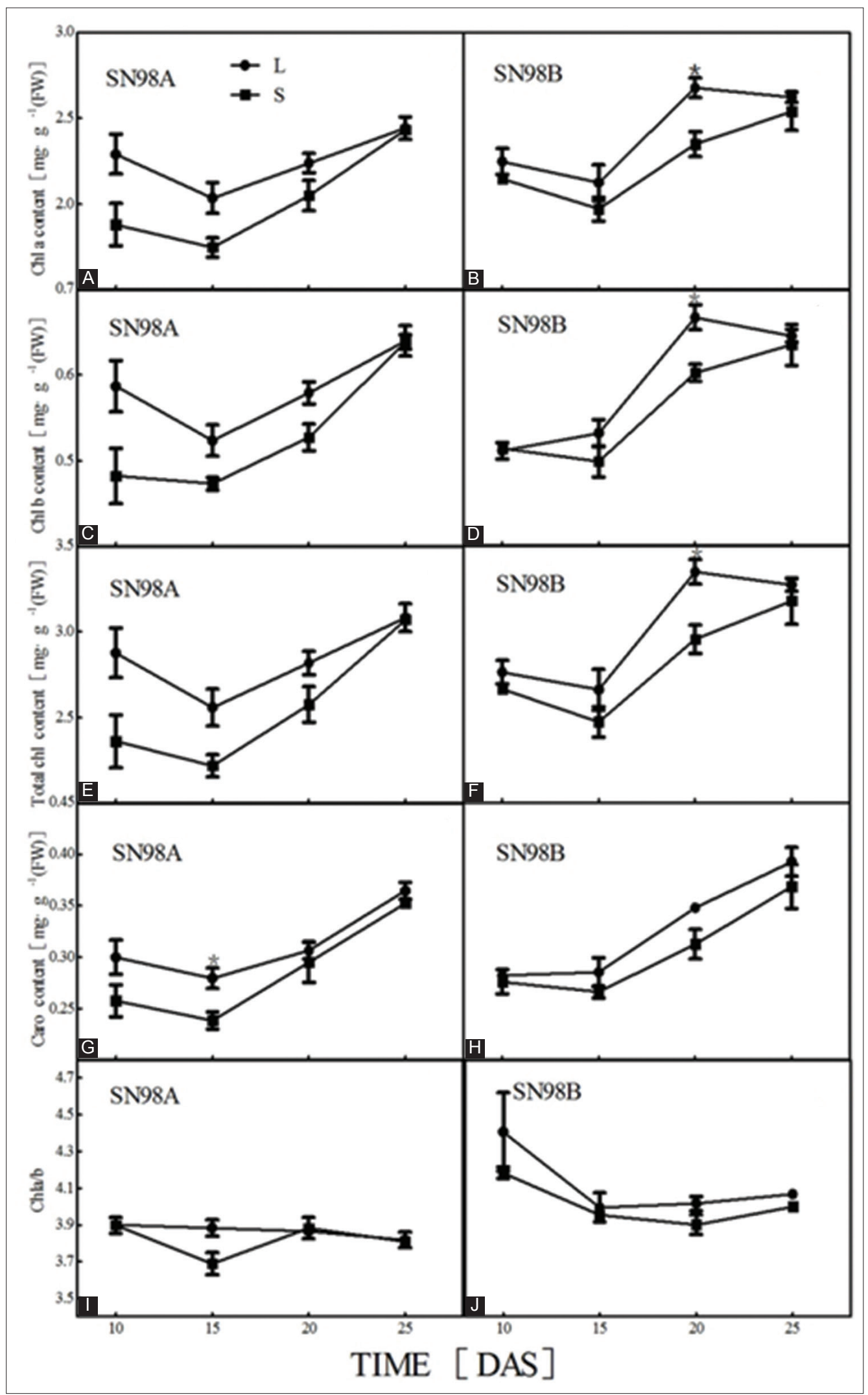

Fig 3. Effects of low light intensity (60\% of ambient sunlight via black net screens $1 \mathrm{~m}$ above the maize canopy) on Chl (chlorophyll) a content (A, B), Chl b content (C, D), total Chl content (E, F), Carotenoid (Caro) content (G, H) and Chl a/b (I, J) of the two maize NILs SN98A and SN98B after low light intensity treatment (DAS indicates days of shading). Values are the means \pm SE. Vertical bars represent standard errors of the means. Asterisks indicate significant differences at $P<0.05$ as analyzed by the least significant difference (LSD) test between ambient sunlight and low light intensity treatment at each time point. $\mathrm{L}$ indicates ambient sunlight treatment, $\mathrm{S}$ indicates low light intensity treatment. 


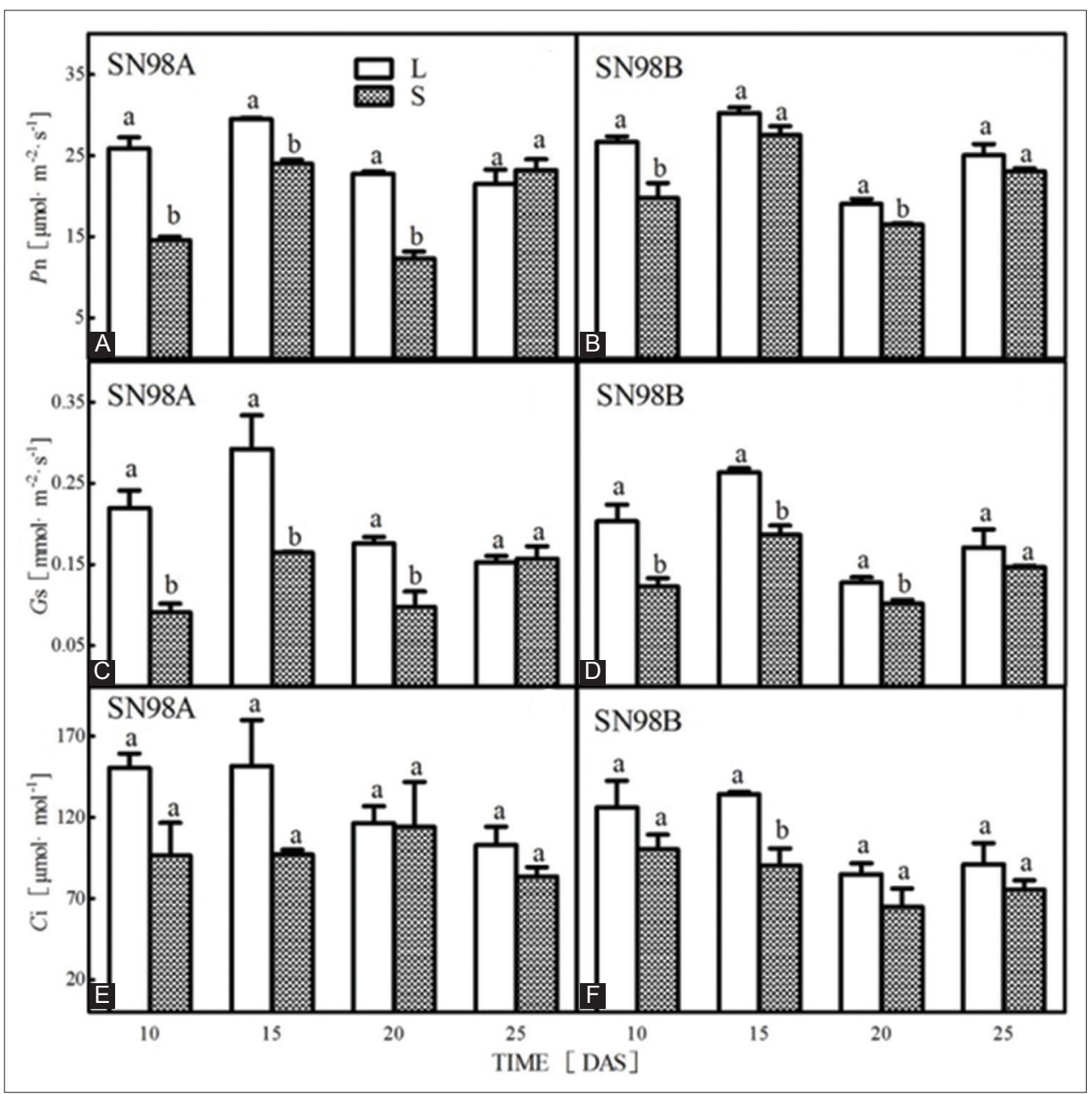

Fig 4. Effects of low light intensity (60\% of ambient sunlight via black net screens $1 \mathrm{~m}$ above the maize canopy) on net photosynthetic rate (Pn) $(A, B)$, stomatal conductance $(\mathrm{Gs})(\mathrm{C}, \mathrm{D})$, and intercellular $\mathrm{CO}_{2}(\mathrm{Ci})(\mathrm{E}, \mathrm{F})$ in the leaves of the two maize NILs SN98A and SN98B after low light intensity treatment (DAS indicates days of shading). Values are the means \pm SE. Vertical bars represent standard errors of the means. Means with different lowercase letters indicate significant differences at $P<0.05$ as analyzed by the least significant difference (LSD) test between ambient sunlight and low light intensity treatments at each time point. $L$ refers to ambient sunlight treatment, $S$ refers to low light intensity treatment.

the stomatal conductance (Zhang et al., 2006), while chlorophyll content and $\mathrm{Chl}$ a/b ratio were also decreased under shading (Griffin et al., 2004). If the content of Chl a increased less than $\mathrm{Chl} b$, the result was a higher $\mathrm{Chl}$ $\mathrm{b} / \mathrm{a}$ ratio. This enhancement of $\mathrm{Chl} \mathrm{b}$ would change the content of the photosynthetic pigments in light-harvesting complex II, and allow the plant leaves to capture sunlight more effectively, particularly the blue light parts in the visible spectrum (Zhang et al., 1995; Hikosaka, 1996). In our study, low light intensity reduced the photosynthetic pigment content (Fig. 3A-H), probably due to the thinner leaves of the affected maize plants which generate fewer mesophyll cells per unit leaf area in low light intensity. In addition, there were differences in the reductions of photosynthetic pigment content between SN98A and SN98B. The change in Chl b occurred more quickly than that in $\mathrm{Chl}$ a, generating an increased $\mathrm{Chl} \mathrm{b} / \mathrm{a}$ ratio in SN98B from 10 to 25 DAS and in SN98A at 15 DAS (Fig. 3I, J). Collectively, these results indicated that the two maize NILs might need different amounts of time (based on the maize varietal characteristic) to accommodate to low light intensity stress by redistributing photosynthetic pigment compositions in the maize leaves, and an increase in the $\mathrm{Chl} \mathrm{b/a} \mathrm{ratio} \mathrm{might} \mathrm{be} \mathrm{a} \mathrm{viable} \mathrm{approach} \mathrm{to} \mathrm{reducing}$ low light intensity injury. The findings also suggested that $\mathrm{SN} 98 \mathrm{~B}$ has greater flexibility in responding to light intensity stress.

Low light intensity treatment resulted in decreases in the photosynthetic rate, stomatal conductance, and intercellular $\mathrm{CO}_{2}$ in the two maize NILs. Meanwhile the dynamic pattern of $\mathrm{Pn}$ and Gs was different from that of Ci in both SN98A and SN98B under low light intensity and ambient sunlight from 10 to 25 DAS (Fig. 4A-F). $\mathrm{Ci}$ is an index used to determine the reason for the low net photosynthetic rate. If net photosynthetic rate (Pn) and intercellular $\mathrm{CO}_{2}$ concentration (Ci) are both low, the low $\mathrm{Pn}$ is attributed to the stomatal limitation; if 


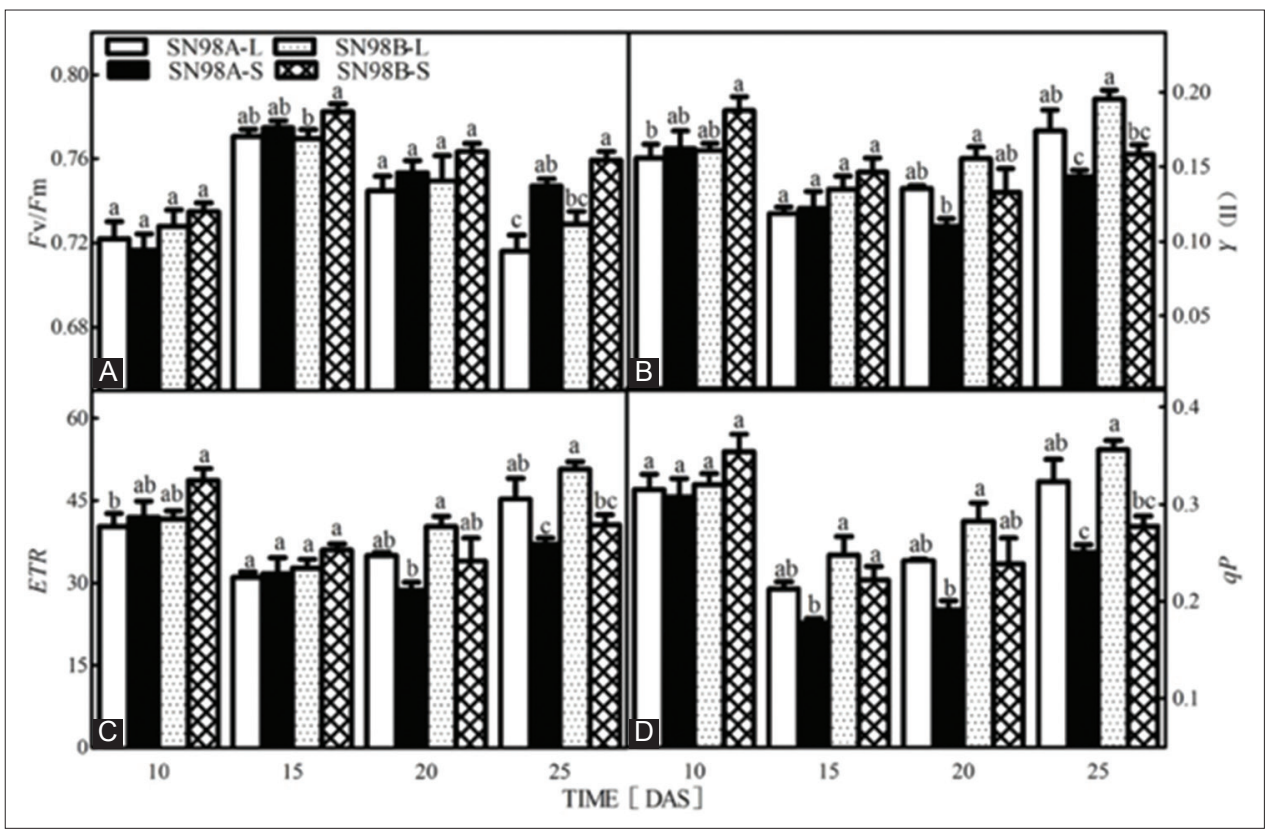

Fig 5. Effects of low light intensity (60\% of ambient sunlight via black net screens $1 \mathrm{~m}$ above the maize canopy) on maximum photochemical quantum yield of PSII $\left(F_{\sqrt{ }} / F_{m}\right)(A)$, effective photochemical quantum yield of PSII $(Y(I I))(B)$, electron transport rate (ETR) (C), and coefficient of photochemical fluorescence quenching $(\mathrm{qP})$ in the leaves of the two maize NILs SN98A and SN98B after low light intensity treatment (DAS indicates days of shading). Values are the means \pm SE. Vertical bars represent standard errors of the means. Means with different lowercase letters in each group indicate significant differences at $P<0.05$ as analyzed by the least significant difference (LSD) test at each time point. L refers to ambient sunlight treatment, $S$ refers to low light intensity treatment.

Pn declines with the increase of $\mathrm{Ci}$, the decline of $\mathrm{Pn}$ is mainly attributed to the non-stomatal limitation (Farquhar and Sharkey, 1982). Stomatal limitation is usually deemed to be the short-term characteristic response to various stresses, while the non-stomatal effect is often supposed to be more pronounced under longer and more serious environmental stress. However, many studies have indicated the decline of photosynthesis in the short term cannot be the exclusive cause of stomatal limitation (Ramanjulu et al., 1998; Yordanov et al., 2000). In our results, trends in the effects of ambient sunlighton $\mathrm{Pn}$ and Gs in SN98A and SN98B were observed along with similar tendencies in $\mathrm{Ci}$ (Fig. $4 \mathrm{~A}-\mathrm{F}$ ). These results showed that for the two maize NILs, stomatal conductance is the main limiting factor that restricts maize assimilation under ambient sunlight. However, under low light intensity, for SN98A, the tendencies in Pn and Gs differed from the tendencies in $\mathrm{Ci}$. These changes were especially evident when reductions in Pn and Gs, along with a relatively high $\mathrm{Ci}$ value at $20 \mathrm{DAS}$, indicated that reduced $\mathrm{CO}_{2}$ availability at the mesophyll cells due to stomatal closure was not the dominant reason for reduced assimilation at 20 DAS. In addition, for SN98A, pronounced declines in Pn and Gs were revealed under low light intensity, whereas $\mathrm{Ci}$ showed a slight reduction compared to ambient sunlight treatment, implying a low carboxylation efficiency. This would signify that under low light intensity stress, nonstomatal limitations prevailed for SN98A. Ramanjulu et al.
(1998) showed that the severity and duration of stress and the ability of a plant species or genotype to withstand that stress determined the significance of stomatal limitation as opposed to non-stomatal limitation. Taken together, these results therefore suggested that stomatal and nonstomatal limitations each played important roles for the two maize NILs under different levels of radiation, and that photosynthetic parameters more likely exhibited greater changes in SN98A than in SN98B under low light intensity stress, rendering SN98A more sensitive to low light intensity than SN98B.

\section{Different responses to low light intensity in chlorophyll fluorescence of the two maize NILs}

Chlorophyll fluorescence can reflect an ability to endure the stresses of environmental changes and the degree to which those stress events injure the photosynthetic organs or tissues of a plant; therefore, fluorescence parameters are a feasible tool for diagnosis of stress-induced changes in PSII, and they are regarded as a crucial marker of the response of photosynthesis to environmental stress (Naumann et al., 2008; Zribi et al., 2009). Due to the sensitivity, convenience, and nonintrusive characteristics of chlorophyll fluorescence, it correctly reflects the changes of photosynthesis in a low light environment (Dai et al., 2009). Compared to ambient sunlight treatment, both Y(II) and ETR were obviously raised under shade conditions, while $\mathrm{F}_{\mathrm{v}} / \mathrm{F}_{\mathrm{m}}$ and NPQ showed no significant 
differences between ambient sunlight and shading treatment (Li et al., 2010). Wang et al.(2015) declared that shade treatment greatly increased the $\mathrm{F}_{\mathrm{v}} / \mathrm{F}_{\mathrm{m}}$ and reduced the ETR, which may be attributed to the decrease in excitation capture efficiency. The Y(II), qP and NPQ values showed significant differences resulting from the use of different cultivars (Wang et al., 2015). In our present experiment, the dynamic change in chlorophyll fluorescence characteristics showed a close correlation with the different cultivars of the two maize NILs. An obvious increase in $\mathrm{F}_{\mathrm{v}} / \mathrm{F}_{\mathrm{m}}$ of $\mathrm{SN} 98 \mathrm{~B}$ was observed (Fig. 5A), as well as decreases in Y(II) and ETR in both maize NILs from 20to 25 DAS (Fig. 5B, C). These might be attributed to the decrease in efficiency of excitation capture under low light intensity.

The qP represents the proportion of open photosystem II reaction centers (Maxwell and Johnson, 2000). A high value of $\mathrm{qP}$ is beneficial for electric charge separation in the light reaction center, and to the electron transport and yield of PSII (Mao et al., 2007). In our study, the differences in qP values indicated that $\mathrm{SN} 98 \mathrm{~A}$ and $\mathrm{SN} 98 \mathrm{~B}$ had differences in electron transport activities in PSII under low light intensity. At 10 DAS, the value of $\mathrm{qP}$ in $\mathrm{SN} 98 \mathrm{~B}$ was higher than under ambient sunlight, while in SN98A it was lower than under ambient sunlight from 10 to $25 \mathrm{DAS}$. The results also illustrated that the responses of chlorophyll fluorescence parameters to low light intensity were different in the two maize NILs, and SN98B had greater adaptability to low light intensity than SN98A. This suggests that low light intensity might contribute to more effective capture and use of light in SN98B via a self-compensation process. These findings were consistent with the findings of our previous research.

O’Neill et al. (2006) indicated that chlorophyll fluorescence measurements could be utilized to distinguish maize photosynthetic responses to different levels of water and to differentiate between stress-tolerant and susceptible maize strains. Chlorophyll fluorescence techniques could be used as a more practical method of indirectly measuring the photosynthetic rates of plant leaves, rather than gas exchange techniques (Earl and Tollenaar, 1999; Adams et al., 2000; Earl and Davis, 2003). In our study (Table 3), $\mathrm{Pn}$ and chlorophyll content were significantly $(P<0.05)$ positively correlated with Y(II), ETR and qP, indicating that measurements of chlorophyll fluorescence could serve to differentiate tolerant maize strains from those susceptible to low light intensity. Thus, we hypothesized that strains of maize tolerant of low light intensity would maintain higher photosynthetic rates vs. susceptible strains, and photosynthetic assessments may offer an efficient method of identifying low light intensity stress-tolerant germplasm.

\section{CONCLUSIONS}

Low light intensity affected the growth, leaf photosynthesis, and chlorophyll fluorescence of the two maize NILs tested (SN98A and SN98B). Low light intensity decreased the content of Chl a, Chl b, and total Chl, as well as Chl $\mathrm{a} / \mathrm{b}$ ratio, while low light intensity reduced $\mathrm{Pn}$ in the two maize NILs, which mainly led to inhibition of assimilated substance accumulationin leaves, resulting in barren stalk development in SN98A. In SN98B, $\mathrm{F}_{\mathrm{v}} / \mathrm{F}_{\mathrm{m}}$ and $\mathrm{qP}$ were increased at $10 \mathrm{DAS}$ under low light intensity. This could result in a smaller reduction in ear development than SN98A. Therefore, improvements in light-harvesting and light-use capability and increasing ear filling under low light intensity stress might be important characteristics for plant breeders. High leaf $\mathrm{F}_{\mathrm{v}} / \mathrm{F}_{\mathrm{m}}$ and $\mathrm{qP}$ values can be selected as indicators of shade tolerance when screening for maize strains tolerant of low light intensity, although we did not find correlations between $\mathrm{F}_{\mathrm{v}} / \mathrm{F}_{\mathrm{m}}$ and $\mathrm{Pn}, \mathrm{Gs}, \mathrm{Ci}$ and $\mathrm{Chl}$ content. Selection of SN98B as a shade-tolerant germplasm would avoid the problem of barren stalk development when light intensity was low. These will be a valuable resource for maize breeders to improve maize production and the resistance of current cultivars under continuous rainy weather and scant-sunlight days.

\section{ACKNOWLEDGEMENTS}

This work was supported by Liaoning province Science and Technology Plan Projects, China. The authors would like to thank The English Doctor for useful advice and English language editing of the manuscript.

\section{Author's contributions}

Q. C. J. implemented the study, analyzed the data and wrote the manuscript. Z. W. guided field experiments. Z.X.M. and L. F. H. provided recommendations for the study. S. Z. S. designed the study and corrected the manuscript.

\section{REFERENCES}

Acreche, M. M., G. Briceño-Félix, J. A. M. Sánchez and G. A. Slafer. 2009. Grain number determination in an old and a modern mediterranean wheat as affected by pre-anthesis shading. Crop Pasture Sci. 60: 271-279.

Adams, M. L., W. A. Norvell, W. D. Philpot and J. H. Peverly. 2000. Spectral detection of micronutrient deficiency in 'Bragg' soybean research. Agron. J. 92: 261-268.

Arnon, D. I. 1949. Copper enzymes in isolated chloroplasts: Polyphenoloxidase in Beta vulgaris. Plant Physiol. 24: 1-15.

Barnes, C. and B. Bugbee. 1992. Morphological responses of wheat to blue light. J. Plant Physiol. 139: 339-342.

Bell, G. E., T. K. Danneberger and M. J. Mcmahon. 2000. Spectral irradiance available for turfgrass growth in sun and shade. Crop Sci. 40: 189-195. 
Cai, Z. Q. 2011. Shade delayed flowering and decreased photosynthesis, growth and yield of Sacha Inchi (Plukenetia volubilis) plants. Ind. Crop Prod. 34: 1235-1237.

Casal, J. J. 1988. Light quality effects on the appearance of tillers of different order in wheat (Triticum aestivum). Ann. Appl. Biol. 112: $167-173$

Chan, W. T. and A. F. Mackenzie. 1972. Effects of shading and nitrogen on growth of corn (Zea mays L.) under field conditions. Plant Soil. 36: 59-70.

Che, H. Z., G. Y. Shi, X. Y. Zhang, R. Arimoto, J. Q. Zhao, L. Xu, B. Wang and Z. H. Chen. 2005. Analysis of 40 years of solar radiation data from China, 1961-2000. Geophys. Res. Lett. 32: 347-354.

Cohan, D. S., J. Xu, R. Greenwald, M. H. Bergin and W. L. Chameides. 2002. Impact of atmospheric aerosol light scattering and absorption on terrestrial net primary productivity. Glob. Biogeochem. Cycles. 16: 37-1-37-12.

Cui, H., J. J. Camberato, L. Jin and J. W. Zhang. 2015. Effects of shading on spike differentiation and grain yield formation of summer maize in the field. Int. J. Biometeorol. 59: 1189-1200.

Dai, Y. J., Z. G. Shen, Y. Liu, L. L. Wang, D. Hannaway and H. F. Lu. 2009. Effects of shade treatments on the photosynthetic capacity, chlorophyll fluorescence, and chlorophyll content of Tetrastigma hemsleyanum diels et gilg. Environ. Exp. Bot. 65: 177-182.

Earl, H. J. and M. Tollenaar. 1999. Using chlorophyll fluorometry to compare photosynthetic performance of commercial maize (Zea mays L.) hybrids in the field. Field Crop Res. 61: 201-210.

Earl, H. J. and R. F. Davis. 2003. Effect of drought stress on leaf and whole canopy radiation use efficiency and yield of maize. Agron. J. 95: 688-696.

Early, E. B., W. O. Mcllrath, R. D. Seif and R. H. Hageman. 1967. Effects of shade applied at different stages of plant development on corn (Zea mays L.) production. Crop Sci. 7: 151-156.

Farquhar, G. D. and T. D. Sharkey. 1982. Stomatal conductance and photosynthesis. Annu. Rev. Plant Physiol. 33: 74-79.

Forster, P. and V. Ramaswamy. 2007. Changes in Atmospheric Constituents and in Radiative Forcing, Cambridge University Press, Cambridge, United Kingdom and New York, NY, USA.

Furuya, M., M. Kanno, H. Okamoto, S. Fukuda and M. Wada. 1997. Control of mitosis by phytochrome and a blue-light receptor in fern spores. Plant Physiol. 113: 677-683.

Genty, B., J. M. Briantais and N. R. Baker. 1989. The relationship between the quantum yield of photosynthetic electron transport and quenching of chlorophyll fluorescence. BBA Gen Subj. 990: 87-92

Grant, R. F., B. S. Jackson, J. R. Kiniry and G. F. Arkin. 1989. Water deficit timing effects on yield components in maize. Agron. J. 81: $61-65$

Greenwald, R., M. H. Bergin, J. Xu, D. Cohan, G. Hoogenboom and W. L. Chameides. 2006. The influence of aerosols on crop production: A study using the CERES crop model. Agric. Syst. 89: 390-413.

Griffin, J. J., T. G. Ranney and D. M. Pharr. 2004. Photosynthesis, chlorophyll fluorescence, and carbohydrate content of illicium taxa grown under varied irradiance. J. Am. Soc. Hortic. Sci. 129: 46-53

Gu, L. H., D. Baldocchi, S. B. Verma, T. A. Black, T. Vesala, E. M. Falge and P. R. Dowty. 2002. Advantages of diffuse radiation for terrestrial ecosystem productivity. J. Geophys. Res. Atmos. 107: ACL 2-1-ACL 2-23.

Hikosaka, K. 1996. Effects of leaf age, nitrogen nutrition and photon flux density on the organization of the photosynthetic apparatus in leaves of a vine (Ipomoea tricolor Cav.) grown horizontally to avoid mutual shading of leaves. Planta. 198: 144-150.

Kanellis, A. K., C. Chan, H. Klee, A. B. Bleecker, J. C. Pech and D. Grierson. 1999. Biology and Biotechnology of the Plant Hormone Ethylene II, Kluwer Academic Publishers, Dordrecht.

Kitajima, M. and W. L. Butler. 1975. Quenching of chlorophyll fluorescence and primary photochemistry in chloroplasts by dibromothymoquinone. BBA Bioenerg. 376: 105-115.

Li, C. H., L. M. Luan, F. Yin, Q. Wang and Y. L. Zhao. 2005. Effects of light stress at different stages on the growth and yield of different maize genotypes (Zea mays L.). Acta Ecol. Sin. 25: 824-830.

Li, H. W., D. Jiang, B. Wollenweber, T. B. Dai and W. X. Cao. 2010. Effects of shading on morphology, physiology and grain yield of winter wheat. Eur. J. Agron. 33: 267-275.

Liu, B., D. N. Qu and X. M. Zhou. 2015. The shoot dry matter accumulation and vertical distribution of soybean yield or yield components in response to light enrichment and shading. Emirates J. Food Agric. 27: 258-265.

Mao, L. Z., H. F. Lu, Q. Wang and M. M. Cai. 2007. Comparative photosynthesis characteristics of Calycanthus chinensis and Chimonanthus praecox. Photosynthetica. 45: 601-605.

Maxwell, K. and G. N. Johnson. 2000. Chlorophyll fluorescence: A practical guide. J. Exp. Bot. 51: 659-668.

Miralle, D. J. and G. A. Slafer. 2007. Sink limitations to yield in wheat: How could it be reduced. J. Agric. Sci. 145: 139-149.

Mu, H., D. Jiang, B. Wollenweber, T. Dai, Q. Jing and W. Cao. 2010. Long-term low radiation decreases leaf photosynthesis, photochemical efficiency and grain yield in winter wheat. J. Agron. Crop Sci. 196: 38-47.

Naumann, J. C., D. R. Young and J. E. Anderson. 2008. Leaf chlorophyll fluorescence, reflectance, and physiological response to freshwater and saltwater flooding in the evergreen shrub, Myrica cerifera. Environ. Exp. Bot. 63: 402-409.

O'Neill, P. M., J. F. Shanahan and J. S. Schepers. 2006. Use of chlorophyll fluorescence assessments to differentiate corn hybrid response to variable water conditions. Crop Sci. 46: 681-687.

Otegui, M. E. 1995. Prolificacy and grain yield components in modern argentinian maize hybrids. Maydica. 40: 371-376.

Ramanathan, V. and Y. Feng. 2009. Air pollution, greenhouse gases and climate change: Global and regional perspectives. Atmos. Environ. 43: 37-50.

Ramanjulu, S., N. Sreenivasulu and C. Sudhakar. 1998. Effect of water stress on photosynthesis in two mulberry genotypes with different drought tolerance. Photosynthetica. 35: 279-283.

Senevirathna, A. M., C. M. Stirling and V. H. Rodrigo. 2003. Growth, photosynthetic performance and shade adaptation of rubber (Hevea brasiliensis) grown in natural shade. Tree Physiol. 23: 705-712.

Shenyang Municipal Bureau of Meteorology. 2013. Shenyang Provincial Meteorological Affair Record Book, Liaoning Science and Technology Press, China.

Sui, Y. H., J. P. Gao, C. H. Liu, W. Z. Zhang, Y. Lan, S. H. Li, J. Meng, Z. J. Xu and L. Tang. 2016. Interactive effects of straw-derived biochar and $\mathrm{N}$ fertilization on soil $\mathrm{C}$ storage and rice productivity in rice paddies of Northeast China. Sci. Total Environ. 544: 203-210.

Tuncel, A. and T. W. Okita. 2013. Improving starch yield in cereals by over-expression of ADPglucose pyrophosphorylase: Expectations and unanticipated outcomes. Plant Sci. 211: 52-60. 
van Kooten, O. and J. F. H. Snel. 1990. The use of chlorophyll fluorescence nomenclature in plant stress physiology. Photosynth. Res. 25: 147-150.

Vityakon, P., S. Sae-Lee and S. Seripong. 1993. Effects of tree leaf litter and shading on growth and yield of paddy rice in Northeast Thailand. Kasesart J. Nat. Sci. 27: 219-222.

Wang, L., F. Deng and W. J. Ren. 2015. Shading tolerance in rice is related to better light harvesting and use efficiency and grain filling rate during grain filling period. Field Crop Res. 180: 54-62.

Wang, L., F. Deng, W. J. Ren and W. Y. Yang. 2013. Effects of shading on starch pasting characteristics of indica hybrid rice (Oryza sativa L). PLoS one. 8: e68220.

Wu, Z. Q. 1991. Study on the production of light and temperature potential of summer maize. Hebei Crop Res. 3: 21-22.

Xu, C., Y. Yin, R. Cai, P. Wang, Y. Ni, J. Guo, E. Chen, T. Cai, Z. Cui, T. Liu, D. Yang and Z. Wang. 2013. Responses of photosynthetic characteristics and antioxidative metabolism in winter wheat to post-anthesis shading. Photosynthetica. 51: 139-150.

Yordanov, I., V. Velikova and T. Tsonev. 2000. Plant responses to drought, acclimation, and stress tolerance. Photosynthetica. 38: 171-186.

Zhang, H. H., M. R. Sharifi and P. S. Nobel. 1995. Photosynthetic characteristics of sun versus shade plants of encelia farinosa as affected by photosynthetic photon flux density, intercellular $\mathrm{CO}_{2}$ concentration, leaf water potential, and leaf temperature. Funct. Plant Biol. 22: 833-841.

Zhang, J. W., S. T. Dong, K. J. Wang, C. H. Hu and L. Peng. 2006. Effects of shading on the growth, development and grain yield of summer maize. Chin. J. Appl. Ecol. 17: 657-662.

Zhang, Q. D., G. M. Jiang, X. G. Zhu, Q. Wang, C. M. Lu, K. Z. Bai, T. Y. Kuang, Q. K. Wei and Z. S. Li. 2001. Photosynthetic capability of 12 genotypes of Triticum aestivum. Chin. J. Plant Ecol. 25: 532-536.

Zhong, X. M. 2014. Research on occurrence mechanism of genetic defect barren stalk of maize (Zea mays L.). Doctor. Shengyang Agriculture University, Shenyang.

Zhong, X. M., Z. S. Shi, F. H. Li and H. J. Huang. 2014. Photosynthesis and chlorophyll fluorescence of infertile and fertile stalks of paired near-isogenic lines in maize (Zea mays L.) under shade conditions. Photosynthetica. 52: 597-603.

Zhou, W. X., X. P. Wang, X. Y. Mu and C. H. Li. 2013. Effects of low-light stress on male and female flower development and pollination and fructification ability of different maize (Zea mays L.) genotypes. Acta Agron. Sin. 39: 2065-2073.

Zribi, L., G. Fatma, R. Fatma, R. Salwa, N. Hassan and R. M. Néjib. 2009. Application of chlorophyll fluorescence for the diagnosis of salt stress in tomato Solanum lycopersicum (variety Rio Grande). Sci. Hortic Amsterdam. 120: 367-372. 